\title{
'I like it instead of maths'. How pupils with moderate learning difficulties in Scottish primary special schools intuitively solved mathematical word problems.
}

\section{Introduction}

Pupils with moderate learning difficulties (MLD) are recognised as the largest group of learners with additional support needs within the educational system (Norwich \& Kelly, 2005; Fletcher-Campbell 2005; HMIe, 2003). With the agenda of inclusion and drive towards ensuring that all learners are actively engaged in their learning it is a matter of equity that the potential of this group of learners is fully realised. It has been argued that traditional views of mathematics teaching underpinned by behaviourist theory continue to dominate classroom practice (Handal, 2003; Lloyd, 2002). While, historically, it has been proposed that direct instruction is the most effective approach for mathematics instruction (Rosenshine, 1987), particularly for children with learning difficulties (Carnine, 1997) studies have shown that low-attaining pupils and children with learning difficulties are capable of self-initiating learning and can invent, transfer and retain strategies for solving arithmetical problems (Bottge, et al. 2007; Empson, 2003; Baroody, 1996; Behrend, 2003, 1994). This paper sets out how a group of 24 children with moderate learning difficulties responded to the use of word problems as part of their arithmetic instruction following their teachers' introduction to the principles of Cognitively Guided Instruction (CGI) (Carpenter et al., 1999).

There is a growing body of literature emerging from research in mathematics education with some of this work focussing on the specific nature of the difficulties that children who struggle in their mathematical development present (Jordan, Hannich \& Kaplan, 
2003; Fuchs \& Fuchs, 2002; Geary, Hamson \& Hoard, 2000; Ostad, 1999). However there is little research into the learning of children with moderate learning difficulties (Porter \& Lacey, 2005) across all domains and in particular in mathematics. So although there is evidence of how children who struggle in mathematics present normatively and by deficit, there is less evidence of how children who struggle in all aspects of their learning engage with mathematical problems and in particular how knowledge of this engagement can be used by teachers to support learning. Furthermore there is evidence that children with learning difficulties show similar mathematical performance, in terms of strategy use and learning trajectory, to children without difficulties at a similar stage of mathematical development (Geary 2004; Gonzalez \& Espinel, 2002; Hoard, Geary \& Hamson, 1999; Fletcheer, Huffman, Bray \& Grupe, 1998; Baroody, 1988).

Research has shown that pupils with arithmetical difficulties are responsive to intervention in mathematics (Dowker, 2004) and it has been argued that the development of inclusive practices rests on teachers developing knowledge of what it is that all children do in their learning (Florian, 2008). Although there is evidence that knowledge derived from research can improve practice in mathematics teaching (Empson \& Junk, 2004; Franke \& Kazemi, 2001; Fennema et al., 1996) there is a view that educational research has too little influence on classroom practice (Hiebert, Gallimore \& Stigler, 2002) with the development and application of research to practice in special education considered weak (Byrnes \& Ysseldyke, 2009). The notion that unique pedagogical knowledge is required by teachers to support struggling learners 
has been challenged (Florian, op.cit.; Lewis \& Norwich, 2005). Florian argues convincingly that the interpretation of children's understanding is a crucial element in developing inclusive practices, the application of this knowledge being more useful than identification of learner deficits. This view has been represented in the domain of literacy (Elliot \& Gibbs, 2008). This paper illustrates the capacity that children with moderate learning difficulties have to reveal their mathematical thinking and considers the importance of this insight into informing their instruction.

\section{Cognitively Guided Instruction}

CGI is a professional development programme developed at the University of Wisconsin-Madison, over a period of nearly twenty years through cyclical research and the application of findings to practice. It focuses on the following elements:

- the development of children's mathematical thinking

- instruction that influences this development

- teachers' knowledge and beliefs that influence their instructional practices

- the way that teachers' knowledge, beliefs and practices are influenced by their understanding of children's mathematical thinking (Carpenter, Fennema, Franke, Levi \& Empson, 2000, p.1).

It is an approach to teaching mathematics that includes the use of word problems set out within research-based frameworks to promote learning with understanding. These frameworks provide the basis of teacher professional development in two areas:

- $\quad$ an understanding of word-problem types

- an understanding of children's solution strategies related to these problem types 
A guiding principle of CGI is that instruction should be informed by specific knowledge about how children develop mathematical concepts. CGI is not a prescriptive pedagogy and teachers develop the principles in their classrooms in a variety of ways particularly in terms of classroom management and organization. Common features of a CGI classroom include the use of word problems to engage children with arithmetical concepts and a great deal of discussion of how they solved the problems in their own way. Children are not shown specific strategies to solve word problems but are encouraged to develop their own solution strategies. These strategies might involve the use of manipulatives, drawing, counting or the use of known number facts. The teacher acts as a mediator encouraging pupils to reveal their thinking by sharing and discussing their solution strategies. Consequent instructional decisions are based on the interpretation of this information.

In CGI word problems are used as a basis for introducing and developing mathematical concepts rather than as a means of determining whether children can apply existing abstract number knowledge to a word problem situation. An essential theme that emerged from earlier studies (Carpenter et al., 2000) is that children come to school with intuitive knowledge of mathematics that they can use to solve word problems without formal or explicit instruction on specific number facts and procedures. They do this by following the language of the problems initially by direct modelling, that is by following the language of the problem and modelling the action of the problem. For example in a joining problem such as - 'There are 4 children on the bus. The bus stops 
at a bus stop and 3 more children get on the bus. How many children are on the bus now?'- a child would physically represent the four children with cubes, drawings or fingers and would then physically represent the three children getting on the bus. The child would then join both sets and count from one to find the total. With time this direct modelling is replaced by more efficient counting strategies which in turn give way to the use of number facts. In this way the learning of number facts is not a rote skill but rather is built on an understanding of the relationships between numbers developed through these modelling and counting strategies (Carpenter et al., 1999, p.4). Through attending to the structure of the problems in this way children engage with important mathematical ideas and develop basic concepts of addition, subtraction, multiplication and division. They can then build on this intuitive mathematical knowledge and construct concepts of place value and multidigit computational procedures. Carpenter et al. (ibid) outline the following strategies that children may use to solve problems:

- Direct Modelling: using manipulatives, fingers or drawing to follow the story of the problem exactly to model out a solution. In direct modeling both numerosities within a problem are represented.

- Counting: problems are solved by employing a range of counting strategies; manipulatives, fingers or tally marks may be used to keep track of counting.

- Derived facts: using known number facts to solve problems involving unknown facts.

- Recall: recalling known number facts. 


\section{Research questions}

This paper reports the findings of pupils with moderate learning difficulties capabilities in responding to word problems. Specifically it considers:

Within classroom settings, how do pupils with moderate learning difficulties respond to word problem activities that encourage them to model, generalise and justify their thinking?

\section{Method}

\section{Participants}

The study involved 12 primary teachers and 24 pupils in three Scottish primary schools for children with moderate learning difficulties. The maximum class size in any of the schools was 10 pupils. The sampling was purposeful (Patton, 2002) with the involvement of three special schools permitting a replication logic yielding findings that could be considered more robust. Replication logic involves each case undergoing individual observation and analysis prior to cross-case analysis (Yin, 2003). Given the criteria for admission into MLD schools, the schools and pupils within them could be considered representative of that sector within the particular local authority. Three special schools within the same authority were invited to nominate participant teachers

for the study. These teachers then identified two pupils in their classes who would be the focus of data collection. Criteria for selection was that the pupils should fit a profile of moderate learning difficulties in that the nature of their learning difficulties were global rather than in specific domains. 
Teachers provided profiles of the two pupils within their class. These profiles included a statement of achievement in mathematics taken from pupils' progress records as well as intended 'next steps' taken from the pupils' individualised educational plans (IEPs). This information provided a profile of the pupils at the outset of the intervention and functioned as a frame of reference post-intervention. The study conformed to the requirements of the University of Strathclyde's Ethics Committee

\section{Intervention}

CGI provided a pedagogical framework that was used as a professional development programme with the participating teachers. The teachers were introduced to the principles of CGI through eight hours of professional development. They developed CGI activities with their whole class but gathered data on the two focus pupils identified at the outset of the study.

\section{Data Collection}

Teachers completed recording sheets for each observed child for each of the CGI sessions providing a total of 240 completed recording sheets of CGI activities. These provided the following data:

- Narrative accounts of the child's strategy for attending to the problem

- Comments regarding pupil engagement

- Other reflective comments and observations

- Attached hardcopy and photographic evidence of children's solution strategies 
These recording sheets facilitated cross-case comparisons (Yin, 2003) as well as a record of progress for individual pupils. Hardcopy and photographic evidence of children's work and researchers' fieldnotes provided further data for comparative analysis with teacher interpretations of pupils' strategies.

\section{Analytical framework}

Data gathered within the CGI sessions were collated into thematic charts along with preliminary data drawn from teachers' profiles of the pupils, assessment records and IEPs. These charts were built adhering to Ritchie, Spencer and O'Connor's (2003) iterative analytical framework which facilitated rigorous analysis. Utilising data drawn from multiple sources reflected Lampert's (2001) model for data gathering which recognises the complexity of cases by viewing them from multiple perspectives. Gathering evidence from a range of sources in this way allowed data to be analysed through a wide lens, at the same time each element could be analysed individually. In this sense these multiple perspectives represented an aspect of triangulation that is viewed in terms of the richness of the picture that is produced rather than solely as a means of confirming or verifying findings (Ritchie et al, op.cit.).

It was also possible to analyse the data within the theoretical framework of CGI (Carpenter et al., 1999) and compare this to teachers' interpretations as set out in their recording sheets. The fieldnotes of the researcher-observed CGI sessions were also an important part of the analytical process. These fieldnotes and observations served to validate or contest teachers' recordings and interpretations of the CGI sessions. 


\section{Findings}

The findings are representative of the 24 pupils who were monitored throughout the study. An initial phase of the study, not specifically reported here, involved individual interviews with the participating teachers to gain insight into their knowledge and beliefs about mathematics teaching to pupils with moderate learning difficulties prior to being introduced to CGI. The findings have been presented within the context of four related themes. Initial assessment and planning drawn from preliminary data provides a frame of reference for the responses of the individual pupils within the sample group in respect of formal planning and assessment. Data on Pupil engagement are from teachers' fieldnotes and narratives as well as classroom observations. Children's solution strategies shows what children actually did in response to the word problems and relates their strategies directly to the theoretical framework of CGI (Carpenter et al, 1999). Children's thinking revealed links with the two previous themes and sets out how the children explained their thinking and the insight this gave into their understandings.

\section{Initial assessment and planning}

Each pupil in the study had an Individualised Educational Plan (IEP) and an individual record of assessment. In seven of the twelve classes the pairs of focus pupils had identical planning and next steps set out in the IEPs and recorded assessments. Although the recorded assessment statements for these pairs of pupils were exactly the same, significant differences in the children's mathematical thinking were revealed as 
they engaged with the word problems. Furthermore the next step planning that was set out for individual children was not always appropriate to the stated assessment. For example, Sam (eight year-old) was recorded as: 'can add confidently to 10', 'knows number to 20', 'has recall of facts (doubles) within 10', 'can add $+1,+2,+3$ with materials, with support'. No experience of subtraction was recorded. Next step planning was 'counting order and number recognition to 15 '.

Barry and Shira, (seven year-olds) had individual but identical records of assessment and planning that stated that both children had: 'recall of facts (doubles) within 10'; were 'able to add 1,2 and 3 to single digit'; had no experience of subtraction and 'required support for understanding of language'. Next steps planning for both children was 'counting order and number recognition to 20'. In CGI activities both children were able to solve simple subtraction problems.

Nine year-old Ali was recorded as 'does not have ordinality 6-10', 'has cardinality 1-5, can match number names and symbols', 'difficulty with retention and recall'. Next steps planning was 'addition within 6'. There was no evidence of Ali having had any prior formal introduction to concepts of addition and subtraction. In CGI activities he intuitively solved addition and subtraction problems within 10, and went on to solve a missing addend problem $(6+x=9)$.

Formal assessment records for nine-year old Gordon stated that he did not 'know number facts to 10', nevertheless in the CGI sessions he demonstrated an understanding 
of the relationship between numbers combinations within 10 by solving challenging start unknown problems $(\mathrm{x}+5=10 ; \mathrm{x}-3=5)$ using counting strategies.

Although each pupil in the study had an IEP there was evidence that in all but one class, instructional sequence was driven by pre-determined planning frameworks rather than being informed by individual pupils' conceptual understanding.

\section{Pupil engagement}

Teachers' records and classroom observations showed that all the case study pupils actively engaged in the activities. Any initial hesitance displayed by some children in the initial CGI sessions did not last. One teacher recorded 'Sam has become more relaxed and self-confident and seems to be enjoying himself'. Pupils saw the problems as challenges, teachers commented on children's eagerness to find solutions 'He is prepared to persevere to find a solution to the problem'. In one class of 7 year-olds children were observed making up simple joining and separating problems for the rest of the group to solve.

The children's engagement was also reflected in what they had to say about the CGI sessions:

'It helps you work better, it helps you know your numbers'

'It helps you learn'

'I like this maths because you can count'

'I like it instead of maths. It's good you get to use stuff' 
'It helps you to count'

'You get to use different things'

'I like using my fingers'

'It's easy 'cos I did a bus and I put windows in'

'It helps you in case you are stuck'

'I liked it when there were buses. It helps you know your numbers'

'Cos I learn more'

Only one pupil said that she did not like CGI because it was 'too hard'. The teacher told the researcher to ignore this because 'she always says that'. This pupil was observed by the researcher to be a direct modeller who could not plan ahead. Prior to being asked if she enjoyed CGI the teacher had given her a join change unknown problem $(7+\mathrm{x}=12)$ that she would not have been able to solve. This problem type is discussed below.

\section{Children's solution strategies}

The sample group of 24 children demonstrated the full range of solution strategies outlined by Carpenter et al. (1999). Twenty-two of the pupils directly modelled their solutions to problems. For fifteen of this group, direct modeling was the only strategy they used. Depending on the structure of the problem six of the older pupils (10/11 year olds) moved between direct modeling and counting strategies, sometimes using their fingers or materials to keep track of their counting. There was evidence of one nine-year old pupil moving from only using direct modelling to also using counting strategies. One eleven-year old pupil used derived facts as well as counting strategies. Two eleven year-old pupils direct modelled solutions for simple joining and separating 
problems within 20. Although these two pupils were formally recorded as having recall of facts to 20 , there was no evidence to support the view that they were able to directly retrieve these facts. Their self-initiated strategy was to direct model a solution.

It was noted that younger pupils in the study, who had perhaps had less exposure to formal procedural instruction, were less inhibited in their use of manipulatives. Some older pupils were initially reluctant to use materials. These pupils had not used materials for a while and relied on taught procedures and computational aids such as hundred squares and number lines. However they responded to teachers' encouragement to employ their own methods. For example 11 year-old Aman's initial reluctance to use materials quickly subsided and he developed a flexible approach employing a wide range of strategies including derived facts. He used counting strategies frequently and when necessary he used materials to help him keep track of his counting. Towards the latter stages of the study there was evidence that he was inventing algorithms. For example to solve a joining problem $(48+25=\mathrm{x})$ he used an incrementing strategy, $40+20 \rightarrow 60+8 \rightarrow 68+5=73$. He counted on from 68 to get to 73.

There was also evidence from teachers' records that some pupils were falling back to previously taught strategies and that these were confusing when they had not been understood. For example 10 year-old Pat initially looked for the operation he had been taught, sometimes asking 'is this addition or subtraction?'. This gradually ceased and he began to direct model problems by attending to the problem structure. He also 
learned of the inefficiency of counting in ones for larger numbers stating on one occasion 'it's too high a sum for cubes'. Pat also began to employ counting strategies counting in tens. Towards the end of the CGI sessions his teacher recorded 'Pat is more able to decide how to proceed with problems now. He is discerning what is required more quickly'. For the problem 'There are 24 children on the bus. The bus stops and 10 get off. How many children are left on the bus?', 10 year-old Jake initially tried to solve the problem by writing out a standard algorithm but teacher notes show that he was unsure how to do this and direct modelled a solution instead. The teacher recorded 'Jake was able to describe to the rest of the group and give the correct answer. Trying to write it as a sum was holding him back at the beginning'.

\section{Revealing their thinking}

Children's thinking was made explicit by what they did and by what they said. The teachers' detailed accounts and observations were insightful. Children were able to explain their solutions although initially some of them were unsure about explaining. Seven year-old Rory was recorded as reluctant to explain his solution, 'he found it very difficult to talk about how he achieved his answer', however by the third CGI session the teacher recorded that he 'could explain what he had done when asked.'

It was important not to take children's explanations at face value and to dig deeper. Effective questioning and careful observation provided deeper insight into children's thinking. Sinead, eight years old, said 'I just thinked and I counted and my brain telled me'. Her teacher's note showed that Sinead used her fingers to count on and on asking 
she was able to demonstrate how she did this. In observation 10 year-old Connor also gave 'I did it in my head' as an explanation, but he was observed surreptitiously counting on using his fingers under the desk.

Some children were recorded as initially 'guessing' responses, for example with the problem 'Jordan has 4 toy cars. I give him 3 more. How many does he have now?' the teacher recorded these notes:

'Chris and I read the question together. He then guessed 5. (the problem was reread) Chris then drew 3 cars and counted them, then referred back to the question and drew another car. He then counted 1-2-3-4. He glanced at the question and drew 3 more cars. He then counted from 1 to $7^{\prime}$.

Some pupils were beginning to see connections in the problems and were relating the structure of the problems to mathematical ideas. For the problem, 'Mrs C has 4 yoyos. Mrs $H$ gives her 4 more yoyos. How many yoyos does Mrs $C$ have now?' Sinead direct modelled using cubes, she joined both sets and counted from one. She explained, 'I got 4 cubes and another 4 cubes, I added on more yoyos. Sinead also recognised similarities between problem types without being told, she said 'that's the same kind as the first one' referring to a similar type joining problem.

Pupils learned from their own and others' mistakes as well. Malcolm, 10 years old, was working in a group on the problem Veruca Salt and Charlie Bucket have 24 bars of chocolate between them Charlie has 12 bars. How many bars does Veruca have? 
He watched two other pupils setting out a set of 12 and a set of 24 . As they joined both sets Malcolm interrupted saying 'No, that's too high'. Malcolm explained his solution by separating 12 from 24 . The teacher recorded 'The modelling process [of the others] exposed the flawed thinking and was invaluable to the eventual outcome in terms of understanding'.

\section{Discussion}

The study is consistent with earlier studies (Bootge et al. op.cit, Baroody, 1996, Behrend, op.cit) in finding that the sample group of pupils with learning difficulties were able to invent, transfer and retain strategies for solving arithmetical problems. This current study involved introducing the teachers to the principles of CGI. In this way pupils' responses were linked to how their teachers applied these principles in practice. Knowldege of what pupils did intuitively to solve the problems gave teachers an insight into the children's mathematical thinking. This knowledge of learners is an important element of the kind of knowledge required by teachers for effective mathematics instruction (Carpenter, Fennema, Peterson \& Carey, 1988).

\footnotetext{
All pupils were active participants in CGI sessions and teachers recognised pupils' ability and motivation within these sessions. No teacher expressed concerns about the suitability of CGI for any of the children they were working with. Yet at the initial introductory sessions, prior to teachers using CGI in the classrooms, there was a general expression of concern that the intervention was 'mainstream' and therefore unsuitable. This proved to be unwarranted. Some teachers remarked with surprise that pupils with
} 
moderate learning difficulties employed the same strategies outlined within the CGI framework. The view that children with learning difficulties follow the same developmental trajectory in their conceptualization of mathematics as typical children (Geary, 2004; Baroody, 1988) was sustained. Furthermore every teacher stated that they felt pupils had benefited from working in this way and eight of them specifically stated that they had underestimated the pupils' ability and potential prior to the intervention. This is noteworthy particularly in light of a recent Scottish study which found that pupils with learning difficulties were more disadvantaged by the attributions and low expectations of mainstream teachers than by their special education colleagues (Woolfson, Grant \& Campbell, 2007).

Word problems have been recognised as vehicles for promoting authentic mathematical understanding (Verschaffel \& De Corte, 1997). In spite of the initial concerns expressed by several of the teachers that the language of the word-problems might be problematic for the pupils, there was little evidence to support this in practice. There is evidence that conceptual rewording can improve children's performance on word problems (Santiago, Orrianta \& Verschaffel, 2007). Sometimes minor adjustments of language resolved misunderstandings that were language based. For example during the observed session in Lianne's Primary 7 classroom the following Separate Result Unknown problem $(14-6=\mathrm{X})$ was given:

Ross had 14 football stickers. He gave 6 stickers to Stewart. How many does he have left? 
Johnny began to model this problem by setting out 14 . He then set out 6 , paused and joined it to the set of 14 and began to count from one. As he was counting Lianne repeated the question, amending it to, 'He gave 6 of his stickers to Stewart'. Johnny immediately said, 'oh, I've got it' and proceeded to direct model the problem by separating.

Difficulties that some children demonstrated in recalling the sentence were frequently overcome by restating the problem in 'chunks. For example, Helen who used the context of frogs, plastic logs, and pictures of a pond, would state the whole problem:

There were 8 frogs on a log. 3 frogs jumped into the pool. How many frogs were on the $\log ?$

She would then restate the first part of the problem, (there were 8 frogs on the log) and allow pupils to direct model that part. Following this she stated the next part of the problem allowing children to model the language of the problem. Children with moderate learning difficulties can have problems of working memory resulting in difficulty with sentence recall (Alloway \& Gathercole, 2005). By restating the problems in chunks children were able to engage with the mathematics and direct model solutions while responsibility for recalling all the language of the problem was reduced.

Some pupils who were working on tens and units direct modelled the problems attempting to represent large numbers in ones. For example Malcolm tried to direct model a problem of $(93-48)$ by drawing out 93 circles and lost track of his counting in the process. The inefficient counting strategies displayed by some pupils reflect the 
findings of earlier studies that showed that children with learning difficulties hold onto inefficient strategies by counting in ones (Ostad, 1997; Geary, Hamson \& Hoard, op.cit.). However when the teachers used their knowledge of the children's strategies and purposely designed word problems that encouraged the children to count in tens, both of these pupils began to use base ten materials to direct model problems and began to calculate more efficiently by working with and counting in tens.

Rather than applying knowledge of number facts to solve word problems, by following the structure of the problem the sample group of children with learning difficulties were able to make sense of the problems and build arithmetical meaning. This engagement with the mathematics of the problems is a crucial part of what Fosnot (1996) describes as 'coming to know'. It supports mathematical understanding that is generative and situated in the learning context (Pratt \& Kelly, 2007).

The role of the teacher is critical in this process. There was evidence in the observations that some pupils were hampered in using sense-making approaches, particularly when children's intuitive strategies were constrained. For example in one class the teacher was observed asking pupils to recall facts before being given materials to demonstrate their solutions. It is also problematic if teachers apply their own sophisticated arithmetical knowledge to the problems and expected pupils to solve problems in this sophisticated way. In one classroom Marjorie was observed giving pupils this Join Change Unknown Problem $(7+\mathrm{X}=12)$ : Chelsea has 7 Barbie dolls. Her mum gives 
her some more. Chelsea now has 12 Barbie dolls. How many dolls did her mum give her?

This is a problem of addition, the language of the problem dictates a joining action, not separation and without a more sophisticated understanding of the relationships between the number combinations, a solution by subtraction would not make sense to some children. After the pupils had worked on the problem, Marjorie said, 'Now I'll show you how you do this kind of problem' and proceeded to demonstrate how to solve it by subtraction. If problems are carefully designed to encourage children to use and build on their own intuitive strategies, (and teachers need to know where each child is in their arithmetical thinking), then pupils will follow the language of the problem to come to a solution.

There is a need for a fundamental shift in teachers' thinking about word problems (Verschaffel, Greer \& De Corte, 2000; Gravemeijer, 1997). This shift involves opting for sense-making rather than computational proficiency as the reason for using word problems (Verschaffel et al., ibid, p. 159). Classroom observations of the children within all three schools, supported by evidence gathered by the teachers, showed that children were able to make sense of word problems in this way. However the opportunity to direct model needs to be encouraged in an authentic constructivist manner, any dilution which results in the use of manipulatives that mimics a taught procedure will not necessarily help develop conceptual understanding (Baroody, 1989). How resources are used by teachers is significant for pupils with learning difficulties. Gravemeijer (op.cit.) argues that ' it is not a cognitive deficit as such that causes 
abstention from sense-making, but rather that children are acting in accordance with a typical school mathematics classroom culture' (p.392).

This study provides further evidence in demonstrating the potential of learners who struggle to learn mathematics and concurs with earlier American studies (Empson, op.cit; Baroody, op.cit.; Behrend, op.cit). in highlighting the capacity of this group of learners to make sense of the mathematics they are learning and to make their understanding visible so that teachers can use this information to inform their teaching. It gives further credence to calls for constructivist approaches for pupils with moderate learning difficulties (Watson, 2001,1996; Palincsar, Magnusson, Collins \& Cutter, 2001). The study was carried out with a small group of children and teachers and does not make claims to be generalisable. It adheres to Stake's (1995) proposition that the usefulness of understanding a phenomenon rests in the richness and depth of knowledge of that particular phenomenon and the recognition of this knowledge within other contexts.

\section{Conclusion}

It is well-established that it is not sufficient to view mathematics learning as the acquisition of procedural skills and abstract concepts to be mastered, rather it should be seen as a process of sense-making and problem-solving that is based on the mathematical modelling of reality (De Corte, 2004, Carpenter et al. op. cit.). Within this view the ultimate goal is that students develop a disposition towards their mathematical learning which involves a sense of themselves as learners who construct mathematical 
meaning through engaging in mathematical activity rather than experiencing mathematics instruction as the acquisition of isolated facts and procedures. This study has shown that for the participating pupils with learning difficulties this is a realistic and reasonable expectation but the realisation of this expectation is fundamentally dependent on the knowledge and beliefs of the teacher.

The still extant orthodoxy that, in mathematics teaching, a 'small-steps' curriculum is desirable for pupils with learning difficulties is challenged. Instead a fundamental shift may be required; a move away from systems that seek to ensure that teachers support pupils in reaching pre-determined bench-marked steps and towards developing a growth in teachers' knowledge and understanding about children's arithmetical thinking in such a way that children's conceptual growth can be tracked and this knowledge can be used to inform instruction. 


\section{References}

Alloway, T.P. \& Gathercole, S.E. (2005). The role of sentence recall in reading and language skills of children with learning difficulties. Learning and Individual Differences, 15, 271-282.

Baroody, A. (1996). Self-invented addition strategies by children with mental retardation. American Journal on Mental Retardation, 101, 72-89.

Baroody, A. (1989). Manipulatives don't come with guarantees. Arithmetic Teacher, $37,(2), 4-5$.

Baroody, A. (1988). Mental addition development of children classified as mentally handicapped. Educational Studies in Mathematics, 19, 369-388.

Behrend, J.L. (2003). Learning-disabled students make sense of mathematics. Teaching Children Mathematics, 9, (5), 269-274.

Behrend, J.L. (1994). Mathematical problem-solving processes of primary grade students identified as learning disabled. Unpublished PhD. Thesis, University of Wisconsin - Madison.

Bottge, B.A., Rueda, E., LaRoque, P.T., Serlin, R.C. \& Kwon, J. (2007). Integrating reform-orientated math ijnstruction in special education settings. Learning Disabilities research and Practice, 22, (2), 99-109.

Byrnes, M.K. \& Ysseldyke, J.E. (2009). Reported prevalence of evidence-based instructional practices in special education. Journal of Special Education, 43,(1), 3-11.

Carnine, D. (1997). Instructional design in mathematics for students with learning disabilities. Journal of Learning Disabilities, 30, 130-141. 
Carpenter, T.P, Fenema, E., Franke, M.L., Levi, L. \& Empson, S.B. (2000). Cognitively guided instruction- A research based teacher development program for elementary school mathematics, Report No. 003. National Center for Improving Student Learning and Achievement in Mathematics and Science. University of Wisconsin.

Carpenter, T.P, Fenema, E., Franke, M. L., Levi, L. \& Empson, S.B. (1999). Children's mathematics - Cognitively guided instruction. Portsmouth, NH: Heinemann.

Carpenter, T.P., Fennema, E., Peterson, P.L. \& Carey, D.A. (1988). Teachers' pedagogical content knowledge of students' problem solving in elementary arithmetic. Journal for Research in Mathematics Education, 19, 5, 385-401.

De Corte, E. (2004). Mainstreams and perspectives in research on learning mathematics from instruction. Applied Psychology: An International Review 53(2), 279-310.

Dowker, A. (2004). What works for children with mathematical difficulties? Research Report RR554. University of Oxford: DfES.

Elliot, J. \& Gibbs, S. (2008). Does dyslexia exist? Journal of Philosophy of Education, 42, (3-4), 475-491.

Empson, S. B. (2003). Low-performing students and teaching fractions for understanding: An interactional analysis. Journal for Research in Mathematics Education. 34, (4), 305-343.

Empson, S.B. \& Junk, D. (2004). Teachers' knowledge of children's mathematics after implementing a student-centred curriculum. Journal of Mathematics Teacher Education, 7, 121-144. 
Fennema,E., Carpenter,T.P., Franke, M.L. Levi, L., Jacobs, V.R. \& Empson, S.B. (1996). A longitudinal study of learning to use children's thinking in mathematics instruction. Journal for Research in Mathematics Education, 27, 403-434.

Fletcher-Campbell, F. (2005). Moderate learning difficulties. In A. Lewis \& B. Norwich (Eds.), Special teaching for special children? Pedagogies for inclusion. Berkshire: OUP.

Fletcher, K., Huffman, L., Bray, N. \& Grupe, L. (1998). The use of the microgenetic method with children with disabilities: discovering competence. Early Education and Development, 9, (4), 357-373.

Florian, L. (2008). Special or inclusive education: future trends. British Journal of Special Education, 35,(4), 202-208.

Fosnot, C.T. (1996). Constructivism: Theory, perspectives and practices. NewYork: Teachers' College Press.

Franke, M. L. \& Kazemi, E. (2001). Learning to teach mathematics: Focus on student thinking. Theory into Practice, 40, (2), 102-109.

Fuchs, L. S. \& Fuchs, D. (2002). Mathematical problem -solving profiles of students with mathematics disabilities with and without comorbid reading disabilities. Journal of Learning Disabilities, 35(6), 563-573.

Geary, D.C. (2004). Mathematics and learning disabilities. Journal of Learning Disabilities, 37(1), 4-15.

Geary, D.C., Hamson,C.O. \& Hoard, M.K. (2000). Numerical and arithmetical 
cognition : A longitudinal study of process and concepts deficits in children with learning disability. Journal of Experimental Child Psychology, 77, 236263.

Gonzalez, J.E. J. \& Espinel, A.I.G. (2002). Strategy choice in solving problems: Are there differences between students with learning difficulties, G-V poor performance, and typical achievement students. Learning Disability Quarterly, $25,113-122$.

Gravemeijer, K. (1997). Solving word problems: A case of modelling? Learning and Instruction, 7, 389-397.

Handal, B. (2003). Teachers'mathematical beliefs: A review. The Mathematics Educator, 13 (2), 47-57.

Hiebert, J., Gallimore, R. \& Stigler, J.W. (2002). A knowledge base for the teaching profession: What would it look like and how can we get one? Educational Researcher, 31(5), 3-15.

HMIE (2003). Moving to Mainstream- The inclusion of pupils with special educational needs in mainstream schools. Edinburgh: SEED.

Hoard, M., Geary, D. \& Hamson, C. (1999). Numerical and arithmetical cognition: performance of low and average IQ children. Mathematical Cognition, 5, 65-91.

Jordan, N.C., Hanich, L.B., Kaplan, D. (2003). A longitudinal study of mathematical competencies in children with specific mathematics difficulties versus children with comorbid mathematics and reading difficulties. Child Development, 74(3), $834-850$.

Lampert, M. (2001). Teaching problems and the problems of teaching. New Haven: 
Yale University Press.

Lewis, A. \& Norwich, B. (2005). Special teaching for special children? Pedagogies for inclusion. Maidenhead: Open University Press.

Lloyd, G. (2002). Mathematics teachers' beliefs and experiences with innovative curriculum materials. In G.C. Leder, E. Pehkonen \& G.Törner (Eds.), Beliefs: A hidden variable in mathematics. Dordrect, Netherlands: Kluwer Academic Publishers

Norwich, B. \& Kelly, N. (2005). Moderate learning difficulties and the future of inclusion. London: Routledge-Falmer.

Ostad, S.A. (1997). Developmental differences in addition strategies: comparisons of mathematically disabled and mathematically normal children. Journal of Educational Psychology, 67, 345-357.

Palincsar, A.S., Magnusson, S.J., Collins, K.M. \& Cuter, J. ( 2001). Making science accessible to all: results of a design experiment in inclusive classrooms. Learning Disability Quarterly, 24, 15-34.

Patton, M.Q. (2002). Qualitative research and evaluation methods. Thousand Oaks, Ca: Sage.

Porter, J. \& Lacey, P. (2005). Researching learning difficulties. London: Sage.

Pratt, N. \& Kelly, P. (2007). Mapping mathematical communities: classrooms, research communities and masterclasses. For the Learning of Mathematics, 27, (2), 3439.

Ritchie, J., Spencer, L. \& O’Connor, W. (2003). Carrying out qualitative analysis. In 
J.Ritchie \& J.Lewis (Eds.), Qualitative research practice- A guide for social science students and researchers. London: Sage.

Rosenshine, B.V. (1987). Explicit teaching and teacher training. Journal of Teacher Education, 38,(3), 34-36.

Santiago, V., Orrantia, J. \& Verschaffel, L. 2007). Influence of situational and conceptual rewording on word problem solving. British Journal of Educational Psychology, 77, 829-848.

Stake, R.E. (1995). The art of case study research. London: Sage.

Verschaffel, L \& De Corte, E. (1997). Word problems: a vehicle for promoting authentic mathematical understanding and problem solving in the primary school? In T. Nunes \& P. Bryant, (Eds.), Learning and teaching mathematics- An international perspective. East Sussex: Psychology Press.

Verschaffel, L., Greer, B. \& De Corte, E. (2000). Making sense of word problems. Lisse: Swets \& Zeitlinger.

Watson, J. (2001). Social constructivism in the classroom. Support for Learning, 16, (3), 140-148.

Watson, J. (1996). Reflection through interaction: The classroom experience of pupils with learning difficulties. London: Falmer.

Woolfson, L., Grant, E. Campbell, L. (2007). A comparison of special, general and support teachers' controllability and stability attributions for children's difficulties in learning. Educational Psychology, 27,(2), 295-306.

Yin, R.K. (2003). Case study research-Design and methods ( $3^{\text {rd }}$ edition). Thousand Oaks,Ca: Sage. 